\title{
Local coordination of protons in In- and Sc-doped $\mathrm{BaZrO}_{3}$
}

\author{
Laura Mazzei, Adrien Perrichon, Alessandro Mancini, \\ Lorenzo Malavasi, Stewart F. Parker, Lars Börjesson \\ and Maths Karlsson
}

\section{Published version information}

Citation: L Mazzei et al. "Local coordination of protons in In- and Sc-doped BaZrO3." Journal of Physical Chemistry C, vol. 123, no. 43 (2019): 26065-26072.

DOI: $\underline{10.1021 / a c s . j p c c .9 b 07074}$

This document is the unedited author's version of a Submitted Work that was subsequently accepted for publication in Journal of Physical Chemistry $C$, copyright (CAmerican Chemical Society, after peer review. To access the final edited and published work see DOI above.

Please cite only the published version using the reference above. This is the citation assigned by the publisher at the time of issuing the AAM. Please check the publisher's website for any updates. 


\title{
Local Coordination of Protons in In- and Sc-Doped $\mathrm{BaZrO}_{3}$
}

\author{
Laura Mazzei, ${ }^{1}$ Adrien Perrichon, ${ }^{2}$ Alessandro Mancini, ${ }^{3}$ Lorenzo Malavasi, ${ }^{3}$ Stewart F. Parker ${ }^{4}$ Lars Börjesson ${ }^{1}$ and Maths \\ Karlsson ${ }^{2, *}$
}

\begin{abstract}
Acceptor doped barium zirconate based proton conductors are currently receiving considerable attention because of their promise as electrolytes in future electrochemical devices, such as solid oxide fuel cells, but the defect chemistry, especially in regard to the local coordination environment and dynamics of protons in these materials is unclear. Here, we investigate the local coordination environments and vibrational dynamics of protons in samples of the proton conducting material $\mathrm{BaZr}_{1-x} M_{x} \mathrm{O}_{3} \mathrm{H}_{x}$ with $M=\mathrm{In}$ and Sc, and $x=0.1$ and 0.5 , using inelastic neutron scattering (INS) and infrared (IR) and Raman spectroscopy together with ab initio molecular dynamics (AIMD) simulations. The local coordination of protons is shown to exhibit a rather peculiar dependence on the type and concentration of dopant atoms, as they are found to be similar for $\mathrm{BaZr}_{1-x} \mathrm{Sc}_{x} \mathrm{O}_{3} \mathrm{H}_{x}$ with $x=0.1$ and 0.5 and $\mathrm{BaZr}_{1-x} \mathrm{In}_{x} \mathrm{O}_{3} \mathrm{H}_{x}$ with $x=0.1$, whereas for $\mathrm{BaZr}_{1-x} \mathrm{In}_{x} \mathrm{O}_{3} \mathrm{H}_{x}$ with $x=0.5$ additional protons sites seem to be present. It is argued that these additional proton sites are characterized by local structural arrangements reminiscent of the fully In-substituted material $\mathrm{BaInO}_{3} \mathrm{H}$. The presence of these local structural arrangements points toward different local proton mobilities between $\mathrm{BaZr}_{1-x} \mathrm{In}_{x} \mathrm{O}_{3} \mathrm{H}_{x}$ with $x=0.5$ and the other three materials and a higher rate of proton transfer events in brownmillerite-type local structures.
\end{abstract}

\section{INTRODUCTION}

Proton conducting perovskite type oxides are of interest for application as electrolytes in various electrochemical devices, such as hydrogen sensors and solid oxide fuel cells (SOFCs). $\frac{[12]}{}$ Among the most promising perovskite materials are acceptor doped barium zirconates, of the general formula $\mathrm{BaZr}_{1-x} M_{x} \mathrm{O}_{3-x / 2}(M=$ trivalent cation, $0<x<1)$. The protons are not part of the perovskite lattice, but can be introduced as interstitial species during heat treatment in a humid atmosphere. In the hydrated, proton conducting, form the protons are bound to oxygens of the perovskite lattice, thus forming $-\mathrm{OH}$ defects in the material. At temperatures higher than approximately $300 \mathrm{~K}$, the protons can diffuse throughout the perovskite lattice through a Grotthuss type mechanism, involving the transferring (hopping) of protons from one oxygen to another one. ${ }^{3-7}$ However, fundamental questions pertaining to the defect chemistry of these materials remain, especially in regard to the local coordination environment and dynamics of the protons and how these materials properties depend on the type and concentration of dopant atoms.

Vibrational spectroscopy provides a powerful means for the study of the local coordination environments of protons in proton conducting oxides. The vibrational dynamics of pro-

${ }^{1}$ Department of Physics, Chalmers University of Technology, SE-412 96 Göteborg, Sweden.

${ }^{2}$ Department of Chemistry and Chemical Engineering, Chalmers University of Technology, SE-412 96 Göteborg, Sweden. E-mail: maths.karlsson@chalmers.se; Tel. +46 317726770

${ }^{3}$ Department of Physical Chemistry, IENI-CNR and INSTM, University of Pavia, I 27100, Pavia, Italy

${ }^{4}$ ISIS Neutron and Muon Source, STFC Rutherford Appleton Laboratory, Oxfordshire OX11 0QX, United Kingdom tons are characterized by $\mathrm{O}-\mathrm{H}$ bend $[\delta(\mathrm{O}-\mathrm{H})]$ and $\mathrm{O}-\mathrm{H}$ stretch $[v(\mathrm{O}-\mathrm{H})]$ modes. We showed in a series of preceding infrared (IR) spectroscopy measurements on hydrated samples of $\mathrm{BaZr}_{1-x} \mathrm{In}_{x} \mathrm{O}_{3-x / 2}$ with $x=0.10,0.25,0.50$ and 0.75 that the $v(\mathrm{O}-\mathrm{H})$ dynamics are manifested as thee relatively distinct bands, two at 250 and $290 \mathrm{meV}$, respectively, and a broad band between $c a .310$ and $450 \mathrm{meV} \cdot \frac{89}{90}$ The presence of several $v(\mathrm{O}-\mathrm{H})$ bands and the generally broad nature of the bands reflect the co-existence of several unique local proton environments (proton sites) in the structure of the material. We have further investigated the $v(\mathrm{O}-\mathrm{H})$ vibrational frequency using $a b$ initio calculations for a system corresponding to $12.5 \%$ Indoping and with the proton located in various local structural arrangements. It was found that different structural arrangements result in significantly different spectral response within the broad $310-450 \mathrm{meV}$ band. However, the ab initio calculations did not reproduce the bands as located at 250 and 290 $\mathrm{meV}, \underline{8}$ suggesting they relate to proton sites not captured in the calculations, or, alternatively, are related to higher-order transitions (overtones and combination modes).

A limitation of IR spectroscopy applied to hydrated oxides is its insensitiveness towards $\delta(\mathrm{O}-\mathrm{H})$ modes, which are virtually absent in the IR spectra because of their only very weak, or none, modulation of the electrical dipole moment of the O$\mathrm{H}$ species. With the use of inelastic neutron scattering (INS), which, in comparison to IR spectroscopy, does not rely on any such selection rules and for which all modes are, in principle, measurable, we previously set out to characterize the nature of $\delta(\mathrm{O}-\mathrm{H})$ modes in $\mathrm{BaZr}_{1-x} \mathrm{In}_{x} \mathrm{O}_{3-x / 2}$ with $x=0.20,0.50$, and 0.75 .10 The $\delta(\mathrm{O}-\mathrm{H})$ modes are manifested as a quite structured, band between $c a .70$ and $160 \mathrm{meV} \cdot \frac{10}{10}$ This band mirrors the $v(\mathrm{O}-\mathrm{H})$ band region at higher energies, thus establishing 
that the energies of the $\delta(\mathrm{O}-\mathrm{H})$ and $v(\mathrm{O}-\mathrm{H})$ modes are intrinsically coupled. 10

Following this, in combined INS, IR and ab initio molecular dynamics (AIMD) studies on $\mathrm{BaZr}_{0.5} \mathrm{In}_{0.5} \mathrm{O}_{3} \mathrm{H}_{0.5}$ and $\mathrm{Ba}_{2} \mathrm{In}_{2} \mathrm{O}_{5}\left(\mathrm{H}_{2} \mathrm{O}\right)_{x}, 11112$ we investigated the vibrational spectra over a wide energy range, $\approx 50$ $700 \mathrm{meV}$ for $\mathrm{BaZr}_{0.5} \mathrm{In}_{0.5} \mathrm{O}_{3} \mathrm{H}_{0.5} \frac{11}{11}$ and $\approx 50-500$ $\mathrm{meV}$ for $\mathrm{Ba}_{2} \mathrm{In}_{2} \mathrm{O}_{5}\left(\mathrm{H}_{2} \mathrm{O}\right)_{x} \cdot{ }^{[12}$ Further, in our study of $\mathrm{BaZr}_{0.5} \mathrm{In}_{0.5} \mathrm{O}_{3} \mathrm{H}_{0.5}$ we conducted an analysis of the momentum transfer $(Q)$ dependence of the INS intensity, which aided in the assignment of the different vibrational bands. ${ }^{11}$ Specifically, we showed that the proton vibrational spectra (IR and INS) are complex and constituted of the overlapping spectra of protons in several different local structural environments and also contain contributions from higher-order transitions. ${ }^{11 / 12}$ In particular, we showed that the bands as located at 250 and $290 \mathrm{meV}$ in the spectra of $\mathrm{BaZr}_{0.5} \mathrm{In}_{0.5} \mathrm{O}_{3} \mathrm{H}_{0.5}$ and $\mathrm{Ba}_{2} \mathrm{In}_{2} \mathrm{O}_{5}\left(\mathrm{H}_{2} \mathrm{O}\right)_{x}$, are related to fundamental $v(\mathrm{O}-\mathrm{H})$ modes rather than higher-order transitions. ${ }^{[1] 12}$ Furthermore, we found that the local proton environments for specific protons vary with time as a result of thermally activated vibrations of the perovskite lattice. 11

Building on our previous combined IR, INS and AIMD study on $\mathrm{BaZr}_{0.5} \mathrm{In}_{0.5} \mathrm{O}_{3} \mathrm{H}_{0.5}$ and $\mathrm{Ba}_{2} \mathrm{In}_{2} \mathrm{O}_{5}\left(\mathrm{H}_{2} \mathrm{O}\right)_{x}$, we here expand the dopant modification to include $\mathrm{BaZr}_{1-x} M_{x} \mathrm{O}_{3} \mathrm{H}_{x}$ with $M=\operatorname{Sc}(x=0.1$ and 0.5$)$ and $M=\operatorname{In}(x=0.1)$, as well as add Raman spectroscopy as a complementary tool for probing the vibrational spectra. The aim of the study is to investigate the influence of $M$ and $x$ on the vibrational spectra, to compare with the well-studied vibrational spectra of other proton conducting oxides, $8-10] 13-15$ and to provide insight into the local coordination environment of protons in acceptor-doped barium zirconates.

\section{EXPERIMENTAL SECTION}

\subsection{Sample Preparation and Average-Structural and Thermal Characterization}

Powder samples with the chemical compositions $\mathrm{BaZr}_{1-x} M_{x} \mathrm{O}_{3-x / 2}$, with $M=\mathrm{Sc}(x=0.1$ and 0.5$)$ and $M=\operatorname{In}(x=0.1)$, were prepared by solid state sintering by mixing stoichiometric amounts of $\mathrm{BaCO}_{3}, \mathrm{ZrO}_{2}$, and $\mathrm{Sc}_{2} \mathrm{O}_{3}$ or $\operatorname{In}_{2} \mathrm{O}_{3}$, with the sintering process divided into two heat treatments: $1200{ }^{\circ} \mathrm{C}$ for $8 \mathrm{~h}$, followed by $1325{ }^{\circ} \mathrm{C}$ for $48 \mathrm{~h}$, with intermediate grinding and compacting of pellets between each heat treatment. The synthesis of $\mathrm{BaZr}_{0.5} \mathrm{In}_{0.5} \mathrm{O}_{2.75}$ is described elsewhere. 11 The as-sintered powder samples were loaded with protons by letting them cool from $400{ }^{\circ} \mathrm{C}$ to $200{ }^{\circ} \mathrm{C}$ in a tube furnace with a flow of $\mathrm{N}_{2}$ saturated with water vapor. The hydrated samples of $\mathrm{BaZr}_{1-x} \mathrm{Sc}_{x} \mathrm{O}_{3-x / 2}$ with $x=0.1$ and 0.5 , and of $\mathrm{BaZr}_{1-x} \mathrm{In}_{x} \mathrm{O}_{3-x / 2}$ with $x=0.1$ and 0.5 , are hereafter labelled as $10 \mathrm{Sc} / \mathrm{BZO}, 50 \mathrm{Sc} / \mathrm{BZO}$, 10In/BZO and 50In/BZO, respectively.

Powder X-ray diffraction (PXRD) data were collected on the as-prepared samples, using a Bruker D8 ADVANCE diffractometer operating with $\mathrm{CuK}_{\alpha 1}$ radiation in the $2 \theta$-range of $15-100^{\circ}$. The PXRD patterns confirmed that all materials are monophasic with an average-cubic structure with space group $P m \overline{3} m$ (Fig. S1). Thermogravimetric (TG) analysis was performed on the nominally hydrated samples, using a F1 Iris spectrometer from Netzsch. About $100 \mathrm{mg}$ of each nominally hydrated sample was placed in an alumina crucible and heated in a flow of $\mathrm{N}_{2}(25 \mathrm{~mL} / \mathrm{min})$ from $25^{\circ} \mathrm{C}$ to $900{ }^{\circ} \mathrm{C}$ at a heating rate of $5{ }^{\circ} \mathrm{C} / \mathrm{min}$. The hydrogen contents of the nominally hydrated samples were calculated from the TG data (Fig. S2) by considering the samples to be completely dehydrated at $900{ }^{\circ} \mathrm{C}$. The hydrogen contents, expressed in moles of hydrogen per unit formula of perovskite are $0.14(10 \mathrm{Sc} / \mathrm{BZO})$, 0.13 (10In/BZO), 0.47 (50Sc/BZO, and 0.55 (50In/BZO). The values are in agreement with the maximum values expected based on the hydration of oxygen vacancies created via acceptor doping, meaning that the samples are (within error) fully hydrated, with no signs of additional hydrogen, such as physisorbed water molecules or other hydrogenated chemical species in the materials.

\subsection{Vibrational Spectroscopy}

The Raman spectra were measured over the frequency range $12-120 \mathrm{meV}\left(\approx 97-970 \mathrm{~cm}^{-1}\right)$ using a DILOR XY800 triplegrating spectrometer equipped with a liquid-nitrogen cooled CCD in double subtractive configuration. The measurements were performed in backscattering geometry with the spot size of the sample being approximately $30 \mu \mathrm{m}$ in diameter. The $488 \mathrm{~nm}$ line from an $\mathrm{Ar}^{+} / \mathrm{Kr}^{+}$laser was used for excitation.

The IR spectroscopy measurements were performed in diffuse reflectance mode on the samples over the frequency range 200-550 meV ( $\left.\approx 1600-4400 \mathrm{~cm}^{-1}\right)$, using a Bruker Alpha DRIFT spectrometer. About $100 \mathrm{mg}$ of sample was used for each measurement. A measurement of a rough Au mirror was used as a reference spectrum. An absorbance-like spectrum was derived by taking the logarithm of the ratio between the reference and sample spectra. All measurements were performed at room temperature. The spectrometer was located inside an Ar-atmosphere glove box.

\subsection{Inelastic Neutron Scattering}

The INS spectra were measured on the direct-geometry chopper spectrometer MERLIN 16 at $10 \mathrm{~K}$, using three different incident energies, $E_{\mathrm{i}}=200 \mathrm{meV}(5 \mathrm{meV}, 400 \mathrm{~Hz}), 400 \mathrm{meV}$ $(10 \mathrm{meV}, 550 \mathrm{~Hz})$ and $600 \mathrm{meV}(15 \mathrm{meV}, 600 \mathrm{~Hz})$, where the numbers within the parentheses refer to the resolution 
in energy and to the chopper frequency. Approximately 8 $\mathrm{g}$ of $10 \mathrm{Sc} / \mathrm{BZO}, 8 \mathrm{~g}$ of $10 \mathrm{In} / \mathrm{BZO}$, and $8 \mathrm{~g}$ of $50 \mathrm{Sc} / \mathrm{BZO}$ were loaded into separate aluminum sachets and the sachets into separate indium wire sealed thin-walled aluminum cans. The MERLIN time-of-flight spectra were first converted into INS maps $I(Q, \omega)$, i.e. scattering intensity as a function of both momentum $\left(Q, \AA^{-1}\right)$ and energy $(\omega, \mathrm{meV})$ transfer, 17 and the maps were subsequently analyzed using the software MSLICE. 18

\section{COMPUTATIONAL DETAILS}

AIMD simulations were performed within the DFT framework using a plane-wave pseudo-potential approach as implemented in VASP.19-21 The ionic core-valence interaction is described using the PAW method, 22123 and the exchangecorrelation part with the semi-local PBE functional. 24

We built structural models consisting of a $2 \times 2 \times 2$ supercell with respect to the $A B \mathrm{O}_{3}$ cubic perovskite cell, containing a total of 40-44 atoms: $8 \mathrm{~A}$ elements $(8 \mathrm{Ba}), 8 \mathrm{~B}$ elements $(\mathrm{Zr}$ or dopant), $24 \mathrm{O}$ and up to $4 \mathrm{H}$. For the low doping level, we consider one dopant (In or Sc) and one hydrogen in the supercell, resulting in a doping level of $12.5 \%$, hence comparable to the $10 \%$ of the measured samples. Since only one dopant is inserted in the structure, only one arrangement over the $B$ site is possible. For the high doping level, we consider four dopants (In or Sc) and four hydrogen atoms in the supercell, resulting exactly in a doping level of 50\%. Regarding the distribution of the $4 \mathrm{Zr}$ and $4 \mathrm{In}$ atoms on the 8 available $B$ sites, we used the same arrangement as described in our previous work, 11 and shown in Fig. 1.

For the localization of the protons over the perovskite lattice, we performed geometry optimization on 8 structural models for the $12.5 \%$ doped phases, starting with the hydrogen in close proximity to the dopant atom, then with increasing distance considering next-neighbor oxygen atoms. For the $50 \%$ phases, we considered 52 structural models for geometry optimization, with a similar approach as previously described for $50 \mathrm{In} / \mathrm{BZO} .11 \mathrm{~A}$ total of 4 and 10 structures were selected for AIMD, for the $12.5 \%$ and $50 \%$ phases, respectively.

The cell parameters were optimized at $T=0 \mathrm{~K}$, then expanded during the thermalization step of the MD to compensate for the residual pressure originating from cell expansion. The AIMD simulations were performed in the NVT ensemble at $T=300 \mathrm{~K}$, using the Nosé-Hoover thermostat, 25 and consist of five 20 ps-long trajectories for each structural model. Neutron weighted vibrational density of states (VDOS), which are comparable to the measured INS spectra, are obtained by power spectral density (PSD) analysis of the atomic velocities, as extracted from the AIMD trajectories.

For each investigated composition and structural model the vibrational density of states (VDOS) were calculated from the

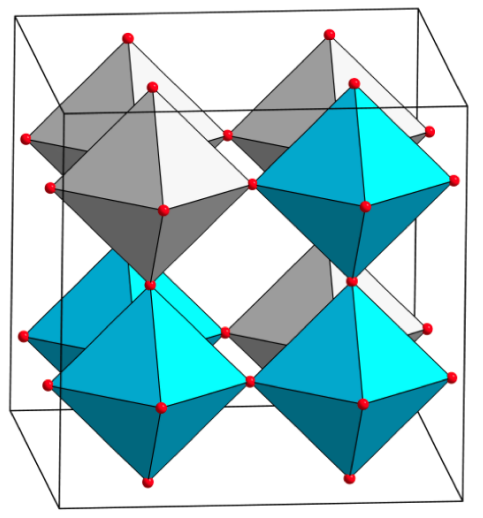

Fig. 1 Schematic illustration of the chosen $\mathrm{Zr}$ and $M$ arrangement, $M=$ In or Sc, in the $2 \times 2 \times 2$ supercell used in the AIMD simulations for the high doping level. The $\mathrm{ZrO}_{6}$ and $M \mathrm{O}_{6}$ octahedra are distinguished by gray and blue color, respectively. Oxygen atoms are shown as red spheres. Ba atoms are omitted for clarity.

AIMD trajectories for each proton independently. As in our previous study on $50 \mathrm{In} / \mathrm{BZO}, \frac{11}{11}$ in the context of the significative inhomogeneous broadening observed experimentally, all the trajectories of a particular composition are merged into a unique structural model. Accordingly, the proton vibrational spectra of each trajectory are normalized and summed.

\section{RESULTS}

\subsection{Raman Spectroscopy}

Fig. 22 (a) shows the Raman spectra of the investigated materials in the range between 12 and $120 \mathrm{meV}\left(\approx 97-970 \mathrm{~cm}^{-1}\right)$. The spectra are characterized by several strong bands and are overall quite similar to each other. The most pronounced bands are found in the range of 10-20, 30-35, 45-50, 60, and 80-90 meV, respectively. Following previous assignments of the Raman spectra of acceptor-doped $\mathrm{BaZrO}_{3}$ materials, 2829 the bands below $\approx 25 \mathrm{meV}$ are assigned to deformational motions of $\mathrm{Ba}-\left[(\mathrm{Zr} / M) \mathrm{O}_{6}\right]$ units, whereas the bands above $\approx 25$ $\mathrm{meV}$ are related to vibrational modes involving oxygen atoms. For the weakly doped materials (10Sc/BZO and 10In/BZO), the spectra are overall very similar, suggesting that the nature of the dopant atom does not affect the local structural properties significantly. The only significant difference regards the position of the bands below $40 \mathrm{meV}$, which are found at slightly higher energies for $10 \mathrm{Sc} / \mathrm{BZO}$ with respect to $10 \mathrm{In} / \mathrm{BZO}$. For the materials with a higher level of doping, some spectral changes are revealed. For the Sc-doped materials, the spectrum of $50 \mathrm{Sc} / \mathrm{BZO}$ features new peaks at approx- 
imately 45, 70, 90 and $105 \mathrm{meV}$. For the In-doped materials, no additional bands are observed. This points toward that the doping with $\mathrm{Sc}$ has a somewhat stronger effect on the local structure of BZO than In.
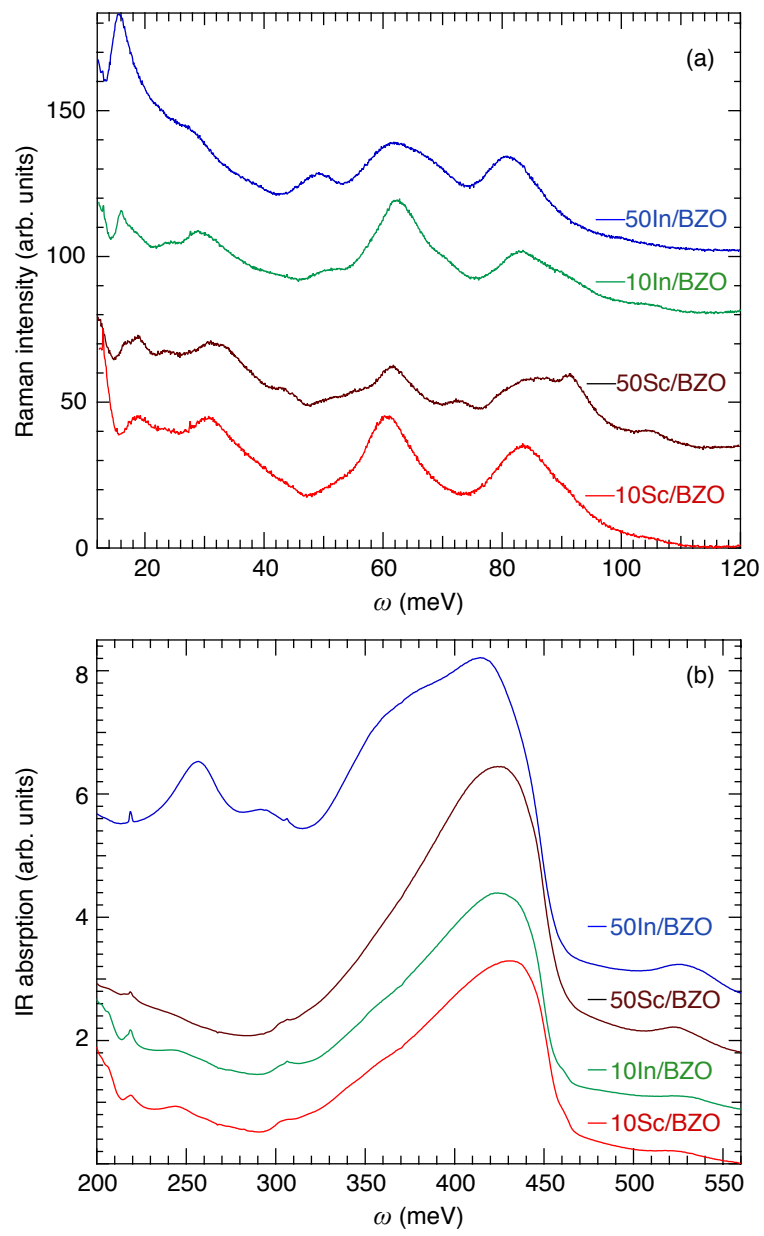

Fig. 2 (a) Raman spectra of $10 \mathrm{Sc} / \mathrm{BZO}, 50 \mathrm{Sc} / \mathrm{BZO} 10 \mathrm{In} / \mathrm{BZO}$ and $50 \mathrm{In} / \mathrm{BZO}$. (b) IR spectra for the $10 \mathrm{Sc} / \mathrm{BZO}, 10 \mathrm{In} / \mathrm{BZO}, 50 \mathrm{Sc} / \mathrm{BZO}$ and 50In/BZO samples. The spectra have been vertically separated for clarity.

\subsection{Infrared Spectroscopy}

Fig. 2 (b) shows the room temperature IR spectra of $10 \mathrm{Sc} / \mathrm{BZO}, 10 \mathrm{In} / \mathrm{BZO}, 50 \mathrm{Sc} / \mathrm{BZO}$ and $50 \mathrm{In} / \mathrm{BZO}$ over the energy range $\omega=200-550 \mathrm{meV}\left(\approx 1600-4400 \mathrm{~cm}^{-1}\right)$, that re-

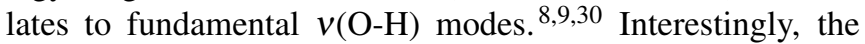
spectra of $10 \mathrm{Sc} / \mathrm{BZO}, 10 \mathrm{In} / \mathrm{BZO}$, and $50 \mathrm{Sc} / \mathrm{BZO}$ are, apart from the generally higher intensity of the heavily doped material, very similar to each other, whereas the spectrum for $50 \mathrm{In} / \mathrm{BZO}$ is markedly different. In particular, the $50 \mathrm{In} / \mathrm{BZO}$

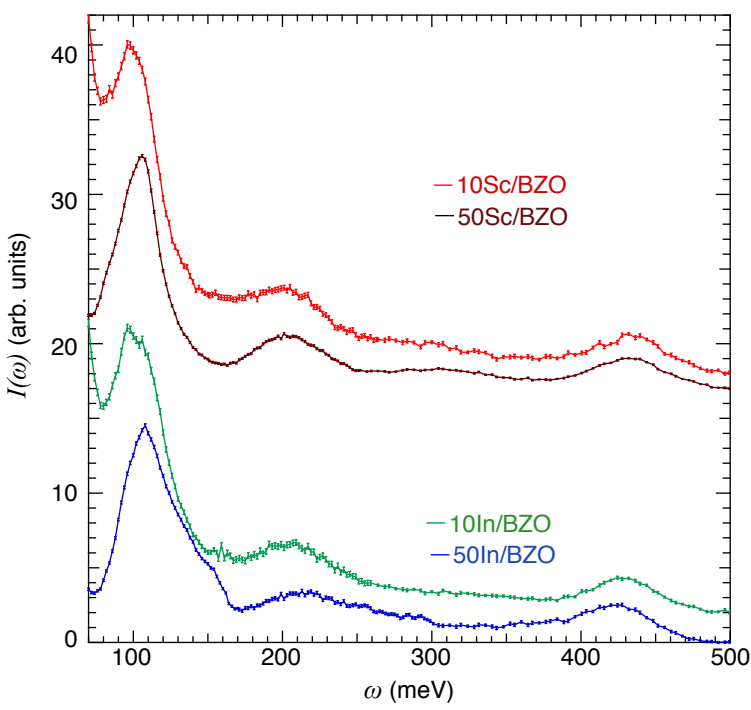

Fig. 3 INS spectra $I(\omega)$ as measured on $10 \mathrm{Sc} / \mathrm{BZO}, 50 \mathrm{Sc} / \mathrm{BZO}$, $10 \mathrm{In} / \mathrm{BZO}$ and $50 \mathrm{In} / \mathrm{BZO}$. The spectra have been vertically offset for clarity.

spectrum exhibits two strong bands at around 250 and 300 $\mathrm{meV}$, respectively, which are markedly less intense /or absent in the spectra of $10 \mathrm{Sc} / \mathrm{BZO}, 10 \mathrm{In} / \mathrm{BZO}$, and $50 \mathrm{Sc} / \mathrm{BZO}$.

\subsection{Inelastic Neutron Scattering}

Fig. 3 shows the INS spectra $I(\omega)$ of all samples, as obtained at $T<10 \mathrm{~K}$ from the measurements on MERLIN, in the $\omega$ range between 70 and $500 \mathrm{meV}$. The corresponding $I(Q, \omega)$ maps measured with $E_{i}=200,400$ and $600 \mathrm{meV}$, respectively, are shown in Fig. 4. Below $70 \mathrm{meV}$ the spectra are dominated by a strong elastic contribution, as one can see also in Fig. 4 . Different parts of the spectra were obtained from the integration of $I(Q, \omega)$ over selected $Q$-ranges. The parts below 170 $\mathrm{meV}$ correspond to the integration over the $Q$ range $4-13 \AA^{-1}$. The spectra in the $\omega=170-300 \mathrm{meV}$ and $\omega=300-400 \mathrm{meV}$ ranges correspond to integration over the $Q$-ranges $7-16 \AA^{-1}$ and $11-17 \AA^{-1}$, respectively.

The most intense feature in each spectrum is the strong band in the range of $\omega \approx 80-130 \mathrm{meV}$, assigned to fundamental $\delta(\mathrm{O}-\mathrm{H})$ modes. 10111 Weaker and broader features are found around 200 and $400 \mathrm{meV}$, respectively. The $200 \mathrm{meV}$ band is assigned to overtones and combinations of the $\delta(\mathrm{O}-$ $\mathrm{H})$ modes, whereas the band around $400 \mathrm{meV}$ is assigned to $v(\mathrm{O}-\mathrm{H})$ modes. The generally broad nature of the bands suggests the presence of several different $\mathrm{O}-\mathrm{H}$ distances and thus several distinct proton sites in the crystal structure of the material. We notice that the maximum of the INS signal occurs at larger $Q$ values as the transition energy increases (Fig. 4), 

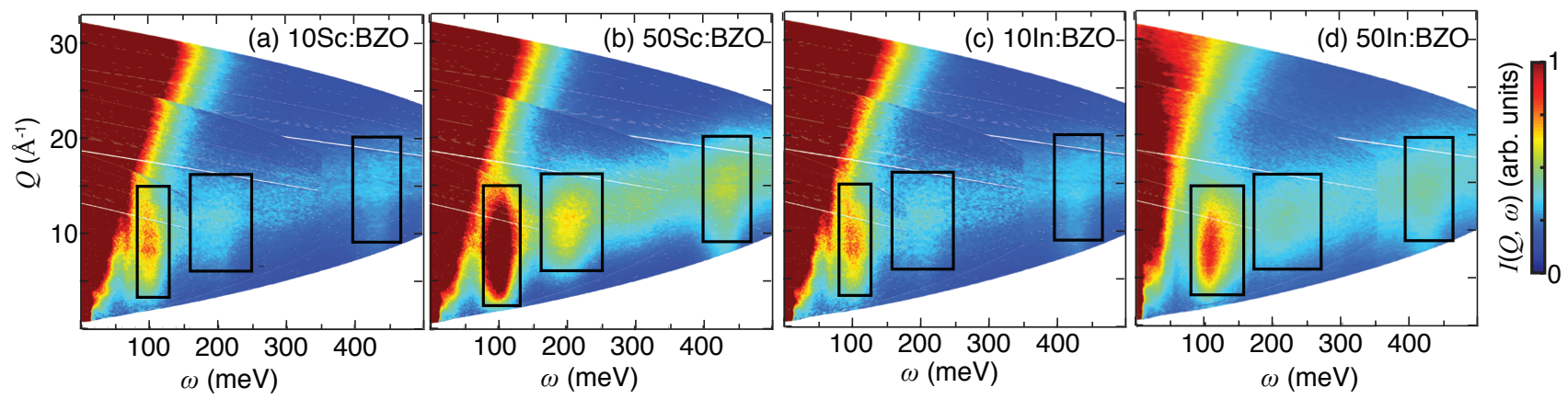

Fig. $4 \mathrm{INS}$ maps as measured at $T<10 \mathrm{~K}$ on the $10 \mathrm{Sc} / \mathrm{BZO}, 50 \mathrm{Sc} / \mathrm{BZO}, 10 \mathrm{In} / \mathrm{BZO}$ and $50 \mathrm{In} / \mathrm{BZO}$ samples. Each map results as the superimposition of three maps obtained using incident energies of $200 \mathrm{meV}, 400 \mathrm{meV}$ and $600 \mathrm{meV}$. The main contributions to the INS intensity, as described in the text, are highlighted in the maps.

exactly as expected following a theoretical analysis of the INS intensity. 11

From Fig. 3 one can also observe that the spectrum of $50 \mathrm{In} / \mathrm{BZO}$ is characterized by a broader $\delta(\mathrm{O}-\mathrm{H})$ band, extending up to $170 \mathrm{meV}$, while the $\delta(\mathrm{O}-\mathrm{H})$ bands for the other compositions extend no further than up to $150 \mathrm{meV}$. Similarly, the second major contribution in the spectra, at $\omega \approx 200 \mathrm{meV}$, is more extended towards higher energies in the spectrum of 50In/BZO with respect to the spectra of the other three materials. Because the upward-shift of the $\delta(\mathrm{O}-\mathrm{H})$ modes is usually associated with a downward-shift of the corresponding $v(\mathrm{O}-$ $\mathrm{H})$ mode, ${ }^{811131}$ the spectral broadening of the INS $\delta(\mathrm{O}-\mathrm{H})$ band for $50 \mathrm{In} / \mathrm{BZO}$ is in agreement with a slight downwardshift of the INS $v(\mathrm{O}-\mathrm{H})$ band as well as the presence of lowenergy IR $v(\mathrm{O}-\mathrm{H})$ features (Fig. 2 (b)).

In order to obtain more quantitative information about the proton local coordination environments, we have performed a peak fit analysis of the spectral regions associated with fundamental $\delta(\mathrm{O}-\mathrm{H})$ and $v(\mathrm{O}-\mathrm{H})$ modes for the $10 \mathrm{In} / \mathrm{BZO}$, $10 \mathrm{Sc} / \mathrm{BZO}$ and $50 \mathrm{Sc} / \mathrm{BZO}$ samples. For 50In/BZO, an analogous analysis was presented earlier,, 11 and is included here for comparison. Fig. 5 and Table 1 show the results of the peak fit analysis for all samples. The peak fitting was done after the subtraction of a linear sloping background, to match the background level of the four different spectra. For 10In/BZO, $10 \mathrm{Sc} / \mathrm{BZO}$ and $50 \mathrm{Sc} / \mathrm{BZO}$, the peak fittings of the $\delta(\mathrm{O}-\mathrm{H})$ $(80-170 \mathrm{meV})$ and $v(\mathrm{O}-\mathrm{H})(340-420 \mathrm{meV})$ regions of the three materials are similar to each other. Both energy regions can be adequately reproduced by three Gaussian components, denoted as $a_{1}, a_{2}$, and $a_{3}$ for the $\delta(\mathrm{O}-\mathrm{H})$ region, and $c_{0}, c_{1}$, and $c_{2}$ for the $v(\mathrm{O}-\mathrm{H})$ region, see Fig. 5 and Table 1 . For $50 \mathrm{In} / \mathrm{BZO}$, one additional Gaussian $\left(a_{4}\right)$ for the $\delta(\mathrm{O}-\mathrm{H})$ region, and two additional Gaussians $\left(c_{3}\right.$ and $\left.c_{4}\right)$ are required. Following our previous work on 50In/BZO, we classified the vibrational energy with the corresponding strength of the hy- drogen bond between the proton and next-nearest oxygen, O$\mathrm{H} \cdots \mathrm{O}$, as medium $(M)$, strong $(S)$, very strong $(V S)$, weak $(W)$, and very weak $(V W)$, respectively. ${ }^{11}$ The classification of the various peaks for all materials is shown in Table 1.

\subsection{Calculated Vibrational Density of States}

Fig. 6 shows the VDOS as obtained from the AIMD simulations for the four different materials. Each spectrum is featured by the contributions from lattice modes $(<90 \mathrm{meV})$, $\delta(\mathrm{O}-\mathrm{H})$ modes $(90-150 \mathrm{meV})$, and $v(\mathrm{O}-\mathrm{H})$ modes $(360-430$ $\mathrm{meV}$ ). Crucially, we observe little to no differences among the different VDOS, indicating that, within the design of our models, the proton vibrational dynamics are virtually independent on the nature of the dopant, In or Sc, and from the amount of doping, light or heavy.

\section{DISCUSSION}

By combining the results from the vibrational spectroscopy and AIMD simulations we can now understand several new features related to the local coordination environments and vibrational dynamics of protons in acceptor doped barium zirconate materials. A particularly important feature of the experimental spectra is that they are generally very similar for $10 \mathrm{Sc} / \mathrm{BZO}, 10 \mathrm{In} / \mathrm{BZO}$, and $50 \mathrm{Sc} / \mathrm{BZO}$, for which it is clear that the majority of protons are located in sites with weak and medium hydrogen bonding, whereas the spectrum of $50 \mathrm{In} / \mathrm{BZO}$ reveals the presence of a significant portion of protons located in sites with strong hydrogen bonds. It can be concluded that for $10 \mathrm{Sc} / \mathrm{BZO}, 10 \mathrm{In} / \mathrm{BZO}$, and $50 \mathrm{Sc} / \mathrm{BZO}$ the local coordination environments of protons are very similar, whereas for 50In/BZO is characterized by additional sites.

In this context, we note that Sc-doped BZO exhibits an average-cubic perovskite structure even for a complete (100\%) 
Table 1 Results from the analysis of the INS intensity $I(\omega) . \omega_{0}$ are the positions of the Gaussian-shaped components used to fit $I(\omega)$, expressed as $e^{-\left(\omega-\omega_{0}\right)^{2} / \sigma^{2}}$. The values are affected by an uncertainty of c.a. $5 \mathrm{meV}$.

\begin{tabular}{lllllll}
\hline \hline \multicolumn{7}{c}{$\omega_{0}(\mathrm{meV})$} \\
Label & $10 \mathrm{Sc} / \mathrm{BZO}$ & $50 \mathrm{Sc} / \mathrm{BZO}$ & $10 \mathrm{In} / \mathrm{BZO}$ & $50 \mathrm{In} / \mathrm{BZO}^{11}$ & Assignment & H-bond strength \\
\hline$a_{1}$ & 97 & 91 & 97 & 93 & $\delta(\mathrm{O}-\mathrm{H})$ & weak \\
$a_{2}$ & 107 & 106 & 110 & 108 & $\delta(\mathrm{O}-\mathrm{H})$ & medium \\
$a_{3}$ & 115 & 123 & 120 & 128 & $\delta(\mathrm{O}-\mathrm{H})$ & medium \\
$a_{4}$ & - & - & - & 150 & $\delta(\mathrm{O}-\mathrm{H})$ & strong \\
$c_{4}$ & - & - & - & 350 & $v(\mathrm{O}-\mathrm{H})$ & strong \\
$c_{3}$ & - & - & - & 375 & $v(\mathrm{O}-\mathrm{H})$ & strong \\
$c_{2}$ & 412 & 414 & 403 & 410 & $v(\mathrm{O}-\mathrm{H})$ & medium \\
$c_{1}$ & 438 & 437 & 428 & 432 & $v(\mathrm{O}-\mathrm{H})$ & weak \\
$c_{0}$ & 465 & 464 & 452 & - & $v(\mathrm{O}-\mathrm{H})$ & weak \\
\hline \hline
\end{tabular}

substitution of $\mathrm{Sc}$ for $\mathrm{Zr}(100 \mathrm{Sc} / \mathrm{BZO}),{ }^{32}$ and that the IR spectra of $50 \mathrm{Sc} / \mathrm{BZO}$ and $100 \mathrm{Sc} / \mathrm{BZO}$, $c f$ Fig. 2 (b) and ref. ${ }^{32}$ are essentially the same. Conversely to Sc-doped BZO, Indoped BZO adopts a brownmillerite structure for any Indopant concentration higher than $\approx 75 \% . \underline{82833}$ The brownmillerite structure of $100 \mathrm{In} / \mathrm{BZO}\left(\mathrm{Ba}_{2} \mathrm{In}_{2} \mathrm{O}_{5}\right)$ may be described as an oxygen-deficient variant of the perovskite structure exhibiting alternating layers of $\mathrm{InO}_{6}$ octahedra and $\mathrm{InO}_{4}$ tetrahedra running along the $c$ direction of an orthorhombic unit cell. Of key relevance here, the hydrated form of $\mathrm{Ba}_{2} \mathrm{In}_{2} \mathrm{O}_{5}\left(\mathrm{BaInO}_{3} \mathrm{H}\right)$ is characterized by two distinctly different proton sites, $\mathrm{H}(1)$ and $\mathrm{H}(2)$. The $\mathrm{H}(1)$ proton site is similar to the one expected in the perovskite structure for lower In concentrations, whereas $\mathrm{H}(2)$ is characterized by a considerably more distorted local environment. $\frac{13] 14 / 31 / 34}{1}$ One important consequence of such a distorted environment is that the angle between the covalent and the hydrogen bond is essentially linear for a $\mathrm{H}(2)$ proton site. Further, the $\mathrm{H}(1)$ and $\mathrm{H}(2)$ protons are featured by two distinctly different contributions in the vibrational spectra, located in the $\omega$-range of $400-450 \mathrm{meV}$ for $\mathrm{H}(1)$, and

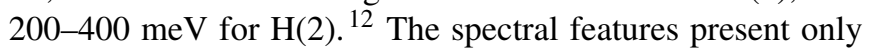
in the spectrum of 50In/BZO thus resemble those associated to the $\mathrm{H}(2)$ protons in $\mathrm{BaInO}_{3} \mathrm{H}$, whereas, as expected, the spectral contribution of the $\mathrm{H}(1)$ protons is comparable with the one observed around $\omega=400-450 \mathrm{meV}$ in all the spectra. This suggests that the very low-frequency $v(\mathrm{O}-\mathrm{H}) \mathrm{IR}$ bands of 50In/BZO are related to proton sites characterized by local structural arrangements reminiscent of the $\mathrm{H}(2)$ site in $\mathrm{BaInO}_{3} \mathrm{H}$. This assignment is further in agreement with the fact that the low-frequency IR bands are more intense in the spectra of $\mathrm{BaInO}_{3} \mathrm{H}$ with respect to $50 \mathrm{In} / \mathrm{BZO}, \frac{12}{12}$ i.e. the relative amount of $\mathrm{H}(2)$ protons is lower in $50 \mathrm{In} / \mathrm{BZO}$ than in $\mathrm{BaInO}_{3} \mathrm{H}$.

We infer from our data that while the local coordination environment of protons is virtually not affected by the in- troduction of Sc dopants, in any amount, the introduction of In dopants leads to the formation of browmillerite-like local distortions. This is in full accordance with our spectral assignment. Crucially, the AIMD simulations show no large spectral differences between the four different materials, but rather point towards a similar coordination environment of the protons independent of the type and concentration of dopant atoms as studied here. The apparent discrepancy between the experimental and computational results points to the fact that the, so called, H(2)-like sites are unstable configurations within our computational models. This is not fully surprising since our simulation are based on structural models that are not designed to capture stable $\mathrm{H}(2)$-like distorted environments. Indeed, the structural models are designed on the basis of a random distribution of both dopant ions on the $B$ sites and protons bonded to the oxygens of the perovskite structure, which suits the crystallographic description of the materials. As such, heterogeneities of the spatial distribution of dopants, such as In-rich domains that may exhibit brownmillerite-type distortions and, thus, stabilise H(2)-type protons, are absent. In this respect, we note that previous work suggested that there is no long-range browmillerite ordering in $50 \mathrm{In} / \mathrm{BZO}, 33$ and that the Raman spectrum in Fig. 2 does not exhibit any spectral signatures reminiscent of the brownmillerite structure.1314 Accordingly, we infer that there are no browmillerite type domains in 50In/BZO, rather the $\mathrm{H}(2)$ like sites are the result of certain local structural distortions. Although the origin of these local structural distortions only in the case of 50In/BZO is at present unclear, it can be noted that $\mathrm{Zr}$ and Sc are transition metals, that are situated close to each other in the periodic table, whereas In is a metal. In particular, one can note that while the effective ionic radii, $r_{\mathrm{i}}$, of all ions are similar $\left[\mathrm{Zr}\left(r_{\mathrm{i}}=72 \mathrm{pm}\right), \mathrm{Sc}\left(r_{\mathrm{i}}=74.5 \mathrm{pm}\right)\right.$, and In $\left(r_{\mathrm{i}}\right.$ $=80 \mathrm{pm})$, in VI coordination], ${ }^{35}$ their absolute atomic hardness are different with the one for $\operatorname{In}(\eta=2.80 \mathrm{eV})$ consider-

$6 \mid 1 \sqrt{11}$ 

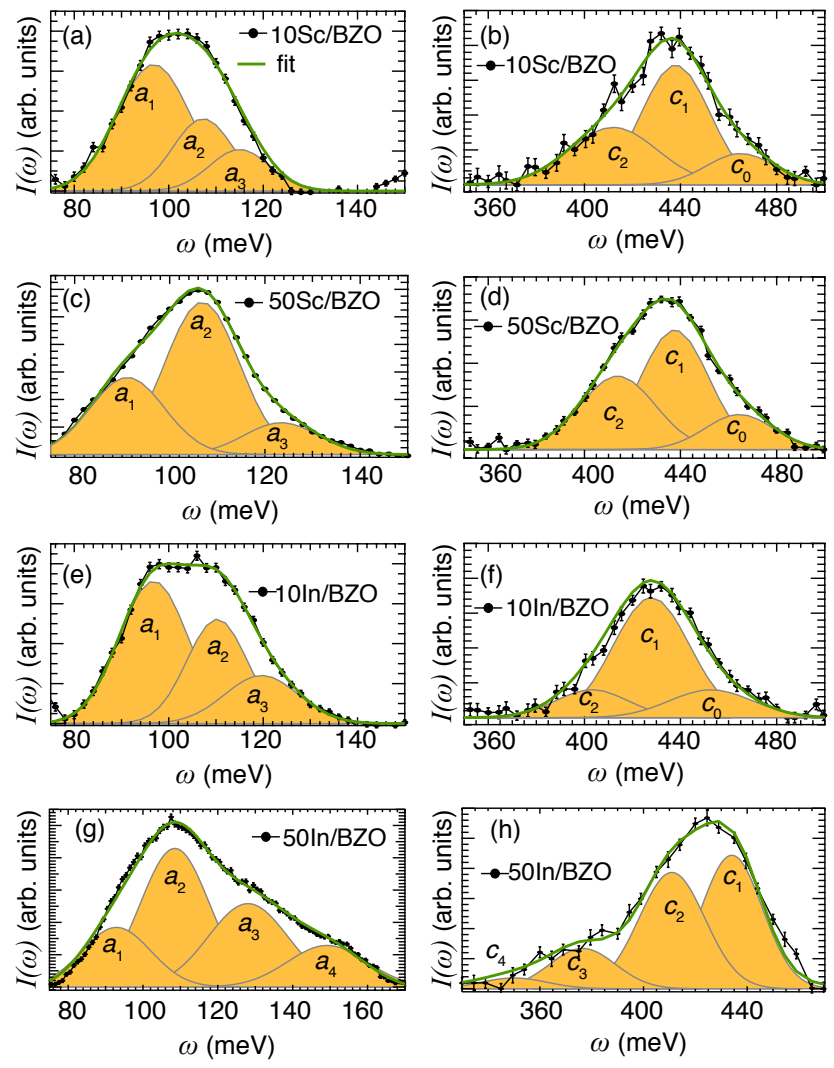

Fig. 5 INS spectra $I(\omega)$ of the investigated samples together with peak-fitted Gaussian components and the total fit (green lines). A linear sloping background was subtracted from the spectra before performing the peak fitting. The spectra in (a), (c) and (e) were obtained by integrating $I(Q, \omega)$ over $Q \in[4-13] \AA^{-1}$. The spectra in (b), (d) and (f) were obtained by integrating $I(Q, \omega)$ over $Q \in[11-17] \AA^{-1}$. The spectra of 50In/BZO $(\mathrm{g}-\mathrm{h})$ are reproduced from ref. ${ }^{11}$ All peak positions are reported in Table 1 .

able lower than for $\mathrm{Zr}(\eta=3.21 \mathrm{eV})$ and $\mathrm{Sc}(\eta=3.20 \mathrm{eV}) . \underline{36}$ This is in accordance with the spectroscopic characteristics of the Y-doped equivalent Y/BZO, for which $\mathrm{Y}$ exhibit a similar ionic radius and absolute hardness to $\mathrm{Zr}$ and $\mathrm{Sc}\left[r_{\mathrm{i}}=90 \mathrm{pm}\right.$, and $\eta=3.19 \mathrm{eV}$, while showing no clear signatures of lowfrequency vibrational bands associated to $\mathrm{H}(2)$ protons in the IR spectrum. ${ }^{[15}$ These observations thus indicate a relationship between local structural distortions associated with the $\mathrm{H}(2)$ protons and the hardness of the dopant atom.

Finally, we remark that the local structural differences, especially in regard to the presence of brownmillerite type local structural distortions and the presence of $\mathrm{H}(2)$ local structures in 50In/BZO, points toward a difference in proton mobilities between $50 \mathrm{In} / \mathrm{BZO}$ and the other three materials as studied here. On a local scale, the proton conduction mecha-

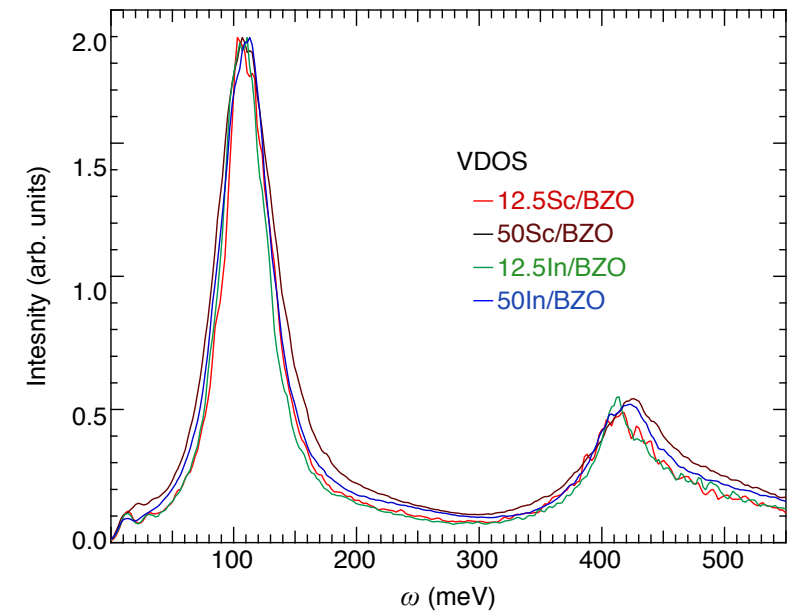

Fig. 6 Vibrational density of states (VDOS) for the four investigated composition, $\mathrm{BaZr}_{1-x} M_{x} \mathrm{O}_{3} \mathrm{H}_{x}$ with $x=0.12$ and 0.5 and $M=\mathrm{In}$ and $\mathrm{Sc}$, calculated as explained in the text.

nism in hydrated perovskites is a two-stage process, involving hydrogen-bond mediated proton transfer between neighbouring oxygen sites, and an $\mathrm{O}-\mathrm{H}$ rotational diffusional motion between such transfers, of which this latter process requires the breaking of the hydrogen bond. In effect, the stronger hydrogen bonding to $\mathrm{H}(2)$ protons compared to $\mathrm{H}(1)$ protons is congruent with a higher proton transfer rate for the $\mathrm{H}(2)$ protons with respect to the $H(1)$ protons, and vice versa for the $\mathrm{O}-\mathrm{H}$ rotational diffusion. Regardless of this effect, we expect $\mathrm{H}(2)$ diffusion to be hindered in the brownmillerite structure due to its inherent lower symmetry, limited number of diffusion pathways, and high proton concentration that leads to a limited amount of vacant sites in the proton vicinity. ${ }^{14}$ The situation may however be different for $50 \mathrm{In} / \mathrm{BZO}$ as the structure remains cubic (high symmetry, high site multiplicity) with no evidence of extended brownmillerite structured domains. This raises questions on the contribution of the $\mathrm{H}(2)$ type protons to the proton diffusivity in 50In/BZO; do they increase the diffusivity by matching the proton transfer and reorientation rates, or do they act as trapping centers due to a very low reorientation rate? The testing of such a hypothesis would require the correlation with local proton diffusivity data on 50In/BZO and $50 \mathrm{Sc} / \mathrm{BZO}$, which can be extracted from quasielastic neutron scattering (QENS) experiments, ${ }^{37]}$ and is an exciting avenue of future research. While previous QENS studies have focused on weakly-doped samples, e.g., $\mathrm{BaZr}_{1-x} \mathrm{In}_{x} \mathrm{O}_{3} \mathrm{H}_{x}$ with $x=0.1,0.2$, and $0.25,677$ and $\mathrm{BaZr}_{0.9} M_{0.1} \mathrm{O}_{3} \mathrm{H}_{x}$ with $M=\mathrm{Sc}$ and $\mathrm{Y}, \frac{[5]}{5}$ for which the $\mathrm{H}(2)$ protons are virtually absent, we note that no QENS study has dealt with the nature and discrimination of localized proton motions in the $\mathrm{H}(2)$-containing ma- 
terial 50In/BZO and its $\mathrm{H}(2)$-free counterpart 50Sc/BZO. We also note that because data of proton conductivity for acceptor doped $\mathrm{BaZrO}_{3}$ have shown to be sensitive to the synthesis route and experimental conditions and, as a result, varies significantly in the literature,, $30 \mid 33] 38,422$ a systematic investigation, on samples prepared under the same conditions, is crucially needed.

\section{CONCLUSIONS}

We have carried out a detailed characterization of the local coordination and vibrational dynamics of protons in hydrated samples of the proton conducting barium zirconates $\mathrm{BaZr}_{1-x} M_{x} \mathrm{O}_{3-x / 2}$ with $M=\mathrm{In}$ and Sc, and $x=0.1$ and 0.5 , using a combination of INS, IR and Raman spectroscopy, and AIMD simulations. The combined analyses of the experimental and theoretical data suggest that the local structure of $50 \mathrm{In} / \mathrm{BZO}$ is characterized by an additional proton site compared to $10 \mathrm{In} / \mathrm{BZO}, 10 \mathrm{Sc} / \mathrm{BZO}$, and $50 \mathrm{Sc} / \mathrm{BZO}$. It is argued that this proton site relates to local structural arrangement reminiscent of those found in the fully In-substituted material $\mathrm{BaInO}_{3} \mathrm{H}$. The relationship between such structural arrangements and the characteristics of the respective dopant atoms have been discussed and indicates that the presence of brownmillerite-type structural distortions only in 50In/BZO has its root in the high In doping concentration and low hardness of the In ions. Furthermore, the presence of these unique local structural distortions points toward different local proton mobilities between $50 \mathrm{In} / \mathrm{BZO}$ and the other three materials as studied here, with a higher rate of proton transfer events in brownmillerite-type local structures.

\section{ASSOCIATED CONTENT}

\section{Supporting Information}

PXRD patterns and TG curves.

\section{ACKNOWLEDGMENTS}

This project was supported by the Swedish Research Council (grant No. 2008-6652, 2010-3519 and 2011-4887) and the Swedish Foundation for Strategic Research (grant No. ICA100001). The STFC Rutherford Appleton Laboratory is thanked for access to neutron beam facilities. Simulations were performed on resources provided by the Swedish National Infrastructure for Computing (SNIC) at PDC Center for High Performance Computing (PDC-HPC).

\section{References}

1 Kilner, J. A.; Burriel, M. Materials for IntermediateTemperature Solid-Oxide Fuel Cells. Annu. Rev. Mater. Res. 2014, 44, 365-393.

2 Malavasi, L.; Fisher, C. A. J.; Islam, M. S. Oxide-Ion and Proton Conducting Electrolyte Materials for Clean Energy Applications: Structural and Mechanistic Features. Chem. Soc. Rev. 2010, 39, 4370-87.

3 Kreuer, K. Proton-Conducting Oxides. Annu. Rev. Mater. Res. 2003, 33, 333-359.

4 Noferini, D.; Koza, M. M.; Fouquet, P.; Nilsen, G. J.; Kemei, M. C.; Rahman, S. M. H.; Maccarini, M.; Eriksson, S.; Karlsson, M. Proton Dynamics in Hydrated $\mathrm{BaZr}_{0.9} M_{0.1} \mathrm{O}_{2.95}(M=\mathrm{Y}$ and $\mathrm{Sc})$ Investigated with Neutron Spin-Echo. J. Phys. Chem. C 2016, 120, 1396313969.

5 Noferini, D.; Koza, M. M.; Karlsson, M. Localized Proton Motions in Acceptor-Doped Barium Zirconates. J. Phys. Chem. C 2017, 121, 7088-7093.

6 Noferini, D.; Frick, B.; Koza, M. M.; Karlsson, M. Proton Jump Diffusion Dynamics in Hydrated Barium Zirconates Studied by High-Resolution Neutron Backscattering Spectroscopy. J. Mater. Chem. A 2018, 6, 7538-7546.

7 Noferini, D.; Koza, M. M.; Rahman, S. M. H.; Evenson, Z.; Nilsen, G. J.; Eriksson, S.; Wildes, A. R.; Karlsson, M. Role of the Doping Level in Localized Proton Motions in Acceptor-Doped Barium Zirconate Proton Conductors. Phys. Chem. Chem. Phys. 2018, 20, $13697-$ 13704.

8 Karlsson, M.; Björketun, M. E.; Sundell, P. G.; Matic, A.; Wahnström, G.; Engberg, D.; Börjesson, L.; Ahmed, I.; Eriksson, S.; Berastegui, P. Vibrational Properties of Protons in Hydrated $\mathrm{BaIn}_{x} \mathrm{Zr}_{1-x} \mathrm{O}_{3-x / 2}$. Phys. Rev. B 2005, 72, 094303.

9 Karlsson, M.; Matic, A.; Zanghellini, E.; Ahmed, I. Temperature-Dependent Infrared Spectroscopy of ProtonConducting Hydrated Perovskite $\mathrm{BaIn}_{x} \mathrm{Zr}_{1-x} \mathrm{O}_{3-x / 2}(x=$ 0.10-0.75). J. Phys. Chem. C 2010, 114, 6177-6181.

10 Karlsson, M.; Matic, A.; Parker, S. F.; Ahmed, I.; Börjesson, L.; Eriksson, S. O-H Wag Vibrations in Hydrated $\mathrm{BaIn}_{x} \mathrm{Zr}_{1-x} \mathrm{O}_{3-x / 2}$ Investigated with Inelastic Neutron Scattering. Phys. Rev. B 2008, 77, 104302.

11 Mazzei, L.; Perrichon, A.; Mancini, A.; Wahnström, G.; Malavasi, L.; Parker, S. F.; Börjesson, L.; Karlsson, M. Local Structure and Vibrational Dynamics in Indium-Doped Barium Zirconate. J. Mater. Chem. A 2019, 7, 7360-7372.

12 Perrichon, A.; Jiménez-Ruiz, M.; Mazzei, L.; Rahman, S. M. H.; Karlsson, M. Local Structure and Vibrational Dynamics of Proton Conducting $\mathrm{Ba}_{2} \mathrm{In}_{2} \mathrm{O}_{5}\left(\mathrm{H}_{2} \mathrm{O}\right)$. J. Mater. Chem. A 2019, 7, 17626-17636. 
13 Bielecki, J.; Parker, S. F.; Ekanayake, D.; Rahman, S. M. H.; Börjesson, L.; Karlsson, M. Short-Range Structure of the Brownmillerite-Type Oxide $\mathrm{Ba}_{2} \mathrm{In}_{2} \mathrm{O}_{5}$ and its Hydrated Proton-Conducting form $\mathrm{BaInO}_{3} \mathrm{H}$. J. Mater. Chem. A 2014, 2, 16915-16924.

14 Bielecki, J.; Parker, S. F.; Mazzei, L.; Börjesson, L.; Karlsson, M. Structure and Dehydration Mechanism of the Proton Conducting Oxide $\mathrm{Ba}_{2} \mathrm{In}_{2} \mathrm{O}_{5}\left(\mathrm{H}_{2} \mathrm{O}\right)_{x}$. J. Mater. Chem. A 2016, 4, 1224-1232.

15 Mburu, C. W.; Gaita, S. M.; Knee, C. S.; Gatari, M. J.; Karlsson, M. Influence of Yttrium Concentration on Local Structure in $\mathrm{BaZr}_{1-x} \mathrm{Y}_{x} \mathrm{O}_{3-\delta}$ Based Proton Conductors. $J$. Phys. Chem. C 2017, 121, 16174-16181.

16 Bewley, R.; Eccleston, R.; McEwen, K.; Hayden, S.; Dove, M.; Bennington, S. M.; Treadgold, J.; Coleman, R. MERLIN, a new High Count Rate Spectrometer at ISIS. Phys. B Condens. Matter 2006, 385-386, 1029-1031.

17 Arnold, O.; Bilheux, J.; Borreguero, J.; Buts, A.; Campbell, S.; Chapon, L.; Doucet, M.; Draper, N.; Ferraz Leal, R.; Gigg, M. et al. Mantid - Data Analysis and Visualization Package for Neutron Scattering and $\mu$ SR Experiments. Nucl. Instrum. Meth. A 2014, 764, 156-166.

18 Coldea, R., Mslice. http://mslice.isis.rl.ac. uk (accessed July 21, 2014).

19 Kresse, G.; Hafner, J. Ab-Initio Molecular Dynamics for Liquid Metals. Phys. Rev. B 1993, 47, 558-561.

20 Kresse, G.; Hafner, J. Ab-Initio Molecular-Dynamics Simulation of the Liquid-Metal-Amorphous-Semiconductor Transition in Germanium. Phys. Rev. B 1994, 49, 1425114269.

21 Kresse, G.; Furthmüller, J. Efficiency of Ab-Initio Total Energy Calculations for Metals and Semiconductors using a Plane-Wave Basis Set. Comput. Mater. Sci. 1996, 6, 1550.

22 Blöchl, P. E. Projector Augmented-Wave Method. Phys. Rev. B 1994, 50, 17953-17979.

23 Kresse, G.; Joubert, D. From Ultrasoft Pseudopotentials to the Projector Augmented-Wave Method. Phys. Rev. B 1999, 59, 1758-1775.

24 Perdew, J. P.; Burke, K.; Ernzerhof, M. Generalized Gradient Approximation Made Simple. Phys. Rev. Lett. 1996, 77, 3865-3868.

25 Bylander, D. M.; Kleinman, L. Energy Fluctuations Induced by the Nosé Thermostat. Phys. Rev. B 1992, 46, 13756-13761.

26 Nosé, S. A Unified Formulation of the Constant Temperature Molecular Dynamics Methods. J. Chem. Phys. 1984, $81,511$.

27 Nosé, S. Constant Temperature Molecular Dynamics Methods. Prog. Theor. Phys. Suppl. 1991, 103, 1-46.

28 Karlsson, M.; Matic, A.; Knee, C.; Ahmed, I.; Eriks- son, S.; Börjesson, L. Short-Range Structure of ProtonConducting Perovskite $\mathrm{BaIn}_{x} \mathrm{Zr}_{1-x} \mathrm{O}_{3-x / 2}(x=0-0.75)$. Chem. Mater. 2008, 20, 3480-3486.

29 Karlsson, M.; Ahmed, I.; Matic, A.; Eriksson, S. ShortRange Structure of Proton-Conducting $\mathrm{Ba}_{0.10} \mathrm{Zr}_{0.90} \mathrm{O}_{2.95}$ ( $M=\mathrm{Y}$, In, Sc and Ga) Investigated with Vibrational Spectroscopy. Solid State Ionics 2010, 181, 126-129.

30 Ahmed, I.; Karlsson, M.; Eriksson, S.; Ahlberg, E.; Knee, C.; Larsson, K.; Azad, A. K.; Matic, A.; Börjesson, L. Crystal Structure and Proton Conductivity of $\mathrm{BaZr}_{0.9} \mathrm{Sc}_{0.1} \mathrm{O}_{3-\delta}$. J. Am. Ceram. Soc. 2008, 91, 30393044.

31 Martinez, J.-R.; Mohn, C. E.; Stølen, S.; Allan, N. L. $\mathrm{Ba}_{2} \mathrm{In}_{2} \mathrm{O}_{4}(\mathrm{OH})_{2}$ : Proton Sites, Disorder and Vibrational Properties. J. Solid State Chem. 2007, 180, 3388-3392.

32 Cervera, R. B.; Miyoshi, S.; Oyama, Y.; Elammari, Y.; Yagi, T.; Yamaguchi, S. Perovskite-Structured $\mathrm{BaScO}_{2}(\mathrm{OH})$ as a Novel Proton Conductor: Heavily Hydrated Phase Obtained via Low-Temperature Synthesis. Chem. Mater. 2013, 25, 1483-1489.

33 Giannici, F.; Longo, A.; Balerna, A.; Kreuer, K.; Martorana, A. Proton Dynamics in $\mathrm{In}: \mathrm{BaZrO}_{3}$ : Insights on the Atomic and Electronic Structure from X-ray Absorption Spectroscopy. Chem. Mater. 2009, 21, 2641-2649.

34 Dervişoğlu, R., R.; Middlemiss, D. S.; Blanc, F.; Lee, Y.L.; Morgan, D.; Grey, C. P. Joint Experimental and Computational ${ }^{17} \mathrm{O}$ and $1 \mathrm{H}$ Solid State NMR Study of $\mathrm{Ba}_{2} \mathrm{In}_{2} \mathrm{O}_{4}(\mathrm{OH})_{2}$ Structure and Dynamics. Chem. Mater. 2015, 27, 3861-3873.

35 Shannon, R. D. Revised Effective Ionic Radii and Systematic Studies of Interatomic Distances in Halides and Chalcogenides. Acta. Cryst. A 1976, 32, 751-767.

36 Pearson, R. G. Absolute Electronegativity and Hardness: Application to Inorganic Chemistry. Inorg. Chem. 1988, 27, 734-740.

37 Karlsson, M. Proton Dynamics in Oxides: Insight Into the Mechanics of Proton Conduction from Quasielastic Neutron Scattering. Phys. Chem. Chem. Phys. 2015, 17, 2638.

38 Kreuer, K.; Adams, S.; Münch, W.; Fuchs, A.; Klock, U.; Maier, J. Proton Conducting Alkaline Earth Zirconates and Titanates for High Drain Electrochemical Applications. Solid State Ionics 2001, 145, 295-306.

39 Ahmed, I.; Eriksson, S.; Ahlberg, E.; Knee, C.; Karlsson, M.; Matic, A.; Börjesson, L.; Engberg, D. Proton Conductivity and Low Temperature Structure of In-doped $\mathrm{BaZrO}_{3}$. Solid State Ionics 2006, 177, 2357-2362.

40 Ahmed, I.; Eriksson, S.; Ahlberg, E.; Knee, C.; Berastegui, P.; Johansson, L.; Rundlöf, H.; Karlsson, M.; Matic, A.; Börjesson, L. Synthesis and Structural Characterization of Perovskite Type Proton Conducting 
$\mathrm{BaZr}_{1-x} \operatorname{In}_{x} \mathrm{O}_{3-\delta}(0 \leq x \leq 0.75)$. Solid State Ionics 2006, 177, 1395-1403.

41 Ahmed, I.; Eriksson, S.-G.; Ahlberg, E.; Knee, C. S. Influence of microstructure on electrical properties in $\mathrm{BaZr}_{0.5} \mathrm{In}_{0.5} \mathrm{O}_{3-\delta}$ proton conductor. Solid State Ionics 2008, 179, 1155-1160.

42 Fabbri, E.; Pergolesi, D.; Traversa, E. Materials challenges toward proton-conducting oxide fuel cells: a critical review. Chem. Soc. Rev. 2010, 39, 4355-69. 


\section{Local Coordination of Protons in In- and Sc-Doped $\mathrm{BaZrO}_{3}$ (Supplementary Information)}

Laura Mazzei, ${ }^{1}$ Adrien Perrichon, ${ }^{2}$ Alessandro Mancini, ${ }^{3}$ Lorenzo Malavasi, ${ }^{3}$ Stewart F. Parker, ${ }^{4}$ Lars Börjesson ${ }^{1}$ and Maths Karlsson ${ }^{2, *}$

${ }^{1}$ Department of Physics, Chalmers University of Technology, SE-412 96 Göteborg, Sweden. ${ }^{2}$ Department of Chemistry and Chemical Engineering, Chalmers University of Technology, SE-412 96 Göteborg, Sweden. E-mail: maths.karlsson@ chalmers.se; Tel. +46 317726770. ${ }^{3}$ Department of Physical Chemistry, IENI-CNR and INSTM, University of Pavia, I 27100, Pavia, Italy. ${ }^{4}$ ISIS Neutron and Muon Source, STFC Rutherford Appleton Laboratory, Oxfordshire OX11 0QX, United Kingdom.

\section{Powder X-Ray Diffraction}

Fig. S1(a) shows the diffractograms of all samples, together with an indication of the position of the different reflections and the Rietveld fits to the data. The parameters obtained from the fits are shown in Table S1. The data confirm that the materials are monophasic with an average-cubic structure with space group $P m \overline{3} m$, and the obtained lattice parameters are in good agreement with previous work. ${ }^{\mathrm{S} 1-\mathrm{S} 6}$

\section{Thermal Gravimetric Analysis}

Fig. S1 (b) shows the TG curves, expressed as \% of the initial mass, of the nominally hydrated samples upon heating from $25^{\circ} \mathrm{C}$ to $900{ }^{\circ} \mathrm{C}$. These curves are in agreement with previous reports. $\mathrm{S} 2, \mathrm{~S} 4, \mathrm{~S} 7-\mathrm{S} 9$

Table S1 Results from the analysis of the PXRD for the four investigated samples. $a$ is the lattice parameter as obtained from the Rietveld fits of the PXRD data and $R_{w p}$ and $\chi^{2}$ are the errors indices ${ }^{\mathrm{S} 10}$ of the fit. The high $\chi^{2}$ obtained for $50 \mathrm{Sc} / \mathrm{BZO}$ is most probably due to trace of impurities in the sample.

\begin{tabular}{lccc}
\hline \hline Sample & $a(\AA)$ & $R_{w p}$ & $\chi^{2}$ \\
\hline $10 \mathrm{Sc} / \mathrm{BZO}$ & $4.1894(2)$ & 7.49 & 1.50 \\
$10 \mathrm{In} / \mathrm{BZO}$ & $4.1926(2)$ & 6.48 & 1.70 \\
50Sc/BZO & $4.2038(3)$ & 6.87 & 5.60 \\
50In/BZO & $4.2005(1)$ & 2.35 & 1.56 \\
\hline \hline
\end{tabular}

\section{References}

[S1] Kreuer, K.; Adams, S.; Münch, W.; Fuchs, A.; Klock, U.; Maier, J. Proton Conducting Alkaline Earth
Zirconates and Titanates for High Drain Electrochemical Applications. Solid State Ionics 2001, 145, 295306.

[S2] Ahmed, I.; Eriksson, S.; Ahlberg, E.; Knee, C.; Berastegui, P.; Johansson, L.; Rundlöf, H.; Karlsson, M.; Matic, A.; Börjesson, L. Synthesis and Structural Characterization of Perovskite Type Proton Conducting $\mathrm{BaZr}_{1-x} \operatorname{In}_{x} \mathrm{O}_{3-\delta}(0 \leq x \leq 0.75)$. Solid State Ionics 2006, 177, 1395-1403.

[S3] Ahmed, I.; Eriksson, S.; Ahlberg, E.; Knee, C.; Karlsson, M.; Matic, A.; Börjesson, L.; Engberg, D. Proton Conductivity and Low Temperature Structure of In-doped $\mathrm{BaZrO}_{3}$. Solid State Ionics 2006, 177, 23572362.

[S4] Ahmed, I.; Karlsson, M.; Eriksson, S.; Ahlberg, E.; Knee, C.; Larsson, K.; Azad, A. K.; Matic, A.; Börjesson, L. Crystal Structure and Proton Conductivity of $\mathrm{BaZr}_{0.9} \mathrm{Sc}_{0.1} \mathrm{O}_{3-\delta}$. J. Am. Ceram. Soc. 2008, 91, 30393044.

[S5] Gilardi, E.; Fabbri, E.; Bi, L.; Rupp, J. L. M.; Lippert, T.; Pergolesi, D.; Traversa, E. Effect of Dopant Host Ionic Radii Mismatch on Acceptor-Doped Barium Zirconate Microstructure and Proton Conductivity. J. Phys. Chem. C 2017, 121, 9739-9747.

[S6] Noferini, D.; Koza, M. M.; Rahman, S. M. H.; Evenson, Z.; Nilsen, G. J.; Eriksson, S.; Wildes, A. R.; Karlsson, M. Role of the Doping Level in Localized Proton Motions in Acceptor-Doped Barium Zirconate Proton Conductors. Phys. Chem. Chem. Phys. 2018, 20, 13697-13704.

[S7] Oikawa, I.; Takamura, H. Correlation among Oxygen Vacancies, Protonic Defects, and the Acceptor Dopant in Sc-Doped $\mathrm{BaZrO}_{3}$ Studied by ${ }^{45} \mathrm{Sc}$ Nuclear Magnetic Resonance. Chem. Mater. 2015, 27, 6660-6667.

[S8] Noferini, D.; Koza, M. M.; Fouquet, P.; Nilsen, G. J.; Kemei, M. C.; Rahman, S. M. H.; Maccarini, M.; Eriksson, S.; Karlsson, M. Proton Dynamics in Hydrated $\mathrm{BaZr}_{0.9} M_{0.1} \mathrm{O}_{2.95}(M=\mathrm{Y}$ and $\mathrm{Sc})$ Investigated 

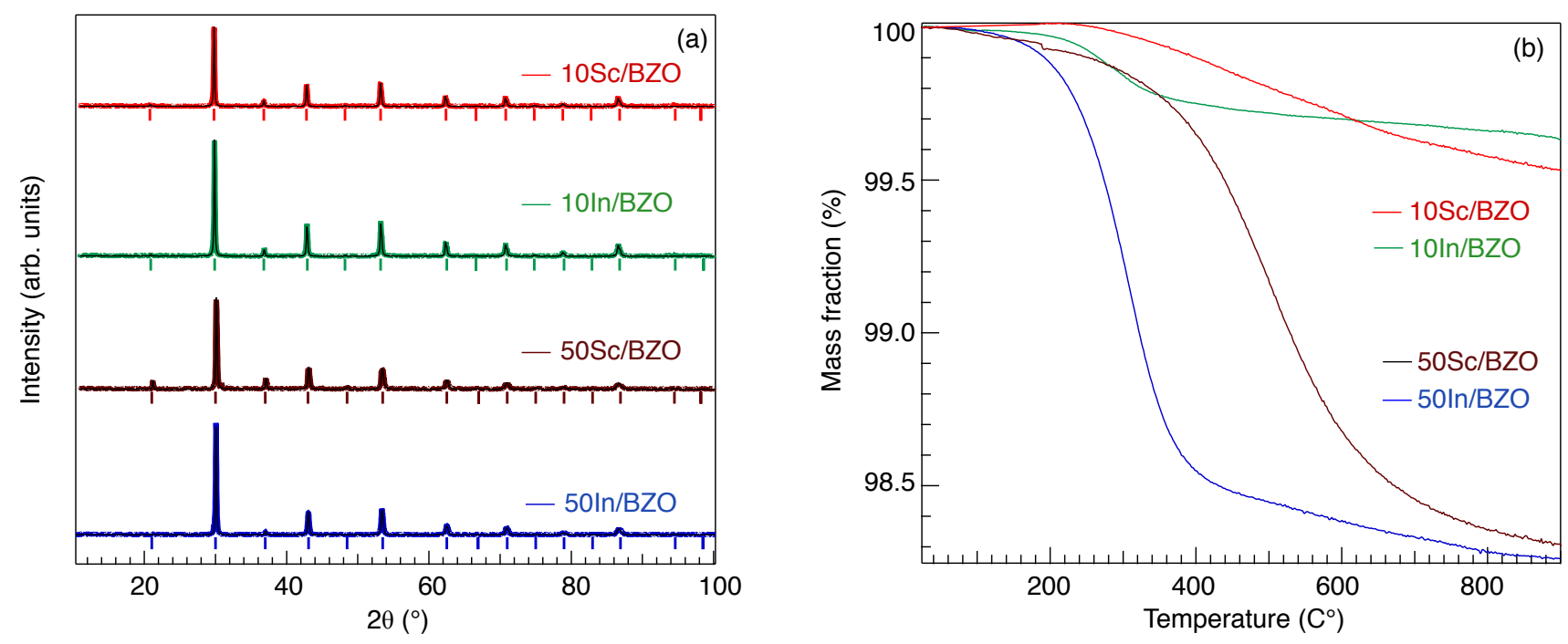

Fig. S1 (a) PXRD patterns of 10In/BZO, 10Sc/BZO, 50Sc/BZO and 50In/BZO, together with Rietveld fits to the data. (b) Results from the TG measurements on the nominally hydrated $10 \mathrm{In} / \mathrm{BZO}, 10 \mathrm{Sc} / \mathrm{BZO}, 50 \mathrm{SC} / \mathrm{BZO}$ and 50In/BZO samples.

with Neutron Spin-Echo. J. Phys. Chem. C 2016, 120, 13963-13969.

[S9] Buannic, L.; Blanc, F.; Hung, I.; Gan, Z.; Grey, C. P. Probing the Local Structures and Protonic Conduction Pathways in Scandium Substituted $\mathrm{BaZrO}_{3}$ by Multinuclear Solid-State NMR Spectroscopy. J. Mater. Chem. 2010, 20, 6322-6332.

[S10] Young, R. A. The Rietveld Method; Oxford University Press: London, U.K., 1993. 